\title{
LUT
}

University

Mission: possible but sensitive - Knowledge protection mechanisms serving different purposes

Olander Heidi, Hurmelinna-Laukkanen Pia, Vanhala Mika

This is a Final draft version of a publication

published by World Scientific Publishers

in International Journal of Innovation Management

DOI: $10.1142 / S 136391961440012 X$

Copyright of the original publication: (@) 2019 World Scientific Publishing Co Pte Ltd

Please cite the publication as follows:

Olander, H., Hurmelinna-Laukkanen, P., Vanhala, M. (2014). Mission: possible but sensitive Knowledge protection mechanisms serving different purposes. International Journal of Innovation Management, vol. 18, iss. 6. DOI: 10.1142/S136391961440012X

This is a parallel published version of an original publication. This version can differ from the original published article. 


\title{
Mission: possible but sensitive - Knowledge protection mechanisms serving different purposes
}

\author{
Heidi Olander*
}

Lappeenranta University of Technology, School of Business

P.O. Box 20, FIN-53851 Lappeenranta, Finland

E-mail: heidi.olander@lut.fi

\section{Pia Hurmelinna-Laukkanen}

Oulu Business School, University of Oulu, P.O. Box 4600, FIN-90014

Oulu, Finland

E-mail: pia.hurmelinna-laukkanen@oulu.fi

\section{Mika Vanhala}

Lappeenranta University of Technology, School of Business P.O. Box 20, FIN-53851 Lappeenranta, Finland

E-mail: mika.vanhala@lut.fi

\begin{abstract}
Innovations have the potential to create value by generating rents (primary appropriability), or they can be used as background knowledge for further innovations and value creation (generative appropriability). Because these possibilities exist, organizations need to make strategic decisions on knowledge sharing with their partners in collaborative innovation. In best cases, primary and generative appropriability are complementarities rather than alternatives: Knowledge sharing with partners for new innovation could be made safer using formal and informal isolating appropriability mechanisms that improve controllability, thereby preserving rent generation possibilities and simultaneously allowing safe knowledge exchange. We use a quantitative sample of 209 Finnish firms to examine how different formal and informal appropriability mechanisms relate to value capture and creation, and whether these relationships are affected by the strategic goal to reduce imitation of competitors or to improve safe knowledge sharing to partners.
\end{abstract}

Keywords: Informal protection; formal protection; value creation; value capture; appropriability

* Corresponding author 


\section{Introduction}

Ahuja et al. (2013) note that inventions and other such creations have potential to generate two types of value: First, they can generate rents as such, being valuable processes to be used by the firm, or becoming commercial products or services, for example. Second, they can be used as background knowledge for further development work. While the idea of background-foreground distinction hardly is new (e.g. Bhatt, 2000; Bessen and Maskin, 2009; Perkmann, 2009), it brings up an important aspect of a firm having to deal with different appropriability issues: The first problem, that has been addressed to quite an extent within existing strategy literature, is how a firm "can capture the greatest share of profits from the problem-solving invention it has developed-that is, benefit from the utility that its invention directly creates for a user". This is the so called primary appropriability issue. The second challenge is how a firm "can capture the greatest share of future inventions that are spawned by its invention and thereby benefit from the new element it has added to the universe of ideas (cf. Fleming, 2001)." This generative appropriability has not received as much attention. (Ahuja et al., 2013, 248).

From the above presented standpoint, value creation and capture can be approached from a different perspective than usually: Whereas the idea is to typically consider first creation of new knowledge and innovation, and then how value is captured from those innovations, here the issue of value capture and (future) creation emerges simultaneously. The question then arises, what kind of factors can contribute to the success of the simultaneous activities and facilitate or ensure the different types of appropriability.

Considering that being able to prevent others from utilizing created innovations freely has been shown to be of relevance with regard to appropriability of innovation (Teece, 1986; Cohen et al., 2000, Ceccagnoli, 2008), and that such an assumption is present with both primary and generative appropriability (Ahuja et al., 2013), mechanisms that increase exclusivity and controllability of the core innovation and the related knowledge can be expected to play a significant role. Intellectual property rights (e.g., patents, copyright, trademarks), contracts, tacitness, secrecy and human resource management are therefore to be reckoned (Hurmelinna-Laukkanen and Puumalainen, 2007; McEvily et al, 2004). However, these mechanisms may have different effects on primary and generative appropriability, and, therefore, value capturing and creation. Some discussion already exists in the field, but literature on protection has often concentrated on one mechanism at a time (e.g., Ceggagnoli, 2009), evaluating that particular mechanism's usability in different situations. Therefore, examination of different mechanisms and their uses in a same study could benefit both research and practice. In particular, the aspect of preventing imitation versus enabling safe knowledge transfer (e.g., Andries \& Faems, 2013) through strategic utilization of the different mechanisms and their specific features (see, e.g., Henkel et al., 2013) calls for deeper understanding. Managers have previously tended to look at intellectual property environment as well as the industry as something beyond their own control (Pisano \& Teece, 2007). However, under right circumstances managers have more choice than what has been traditionally thought in shaping the environment and industry by their strategic choices for using certain appropriability mechanisms (Pisano and Teece, 2007). Appropriability regime is thus not merely something affected by only external factors, but elements of appropriability regime can in fact be used strategically to achieve certain goals (Hurmelinna-Laukkanen \& Puumalainen, 2007; Pisano, 2006). Appropriability studies regarding a network point of view - and collaborative innovation - have been few (Dhanaraj \& Parkhe, 2006; Faems 
et al., 2007), thereby leaving these aspects of value creation and value capturing underresearched. What is known is that knowledge is possessed by organizations, and that they need to make strategic decisions on knowledge sharing with their partners in collaboration, for example. Knowledge sharing should be easier if sharing could be made safer through the use of isolating appropriability mechanisms that improve controllability. In addition, isolating appropriability mechanisms can also help in protecting the knowledge from leaking to competitors ${ }^{1}$ and being imitated (HurmelinnaLaukkanen and Puumalainen, 2007), in which case the isolating mechanisms can promote primary and generative appropriability - and value capture and creation. However, there is still not enough understanding on which mechanisms should be used or the motivations that lead organizations to protect primary and generative knowledge so as to utilize these as complementary, rather than alternative strategies ${ }^{2}$.

Therefore, in this study, our goal is to find out how different formal and informal isolating appropriability mechanisms relate to value capture and creation, and whether these relationships are affected by the strategic goal to a) prevent imitation of competitors or $b$ ) to enable safe knowledge sharing to partners.

\section{Theory and hypotheses}

\subsection{Different isolating mechanisms for value capture and creation}

Prior research indentifies a vast set of appropriability mechanisms that assists a firm to profit from its innovations (see, e.g., review by James et al. 2013, covering top journals). In fact, the challenge is that there are so many different factors, that it becomes quite impossible to address all of these in a meaningful manner. Therefore, following the approach taken by, e.g., Teece (1986), Hurmelinna-Laukkanen and Puumalainen (2007), and Thomä and Bizer (2013), we choose to examine isolating appropriability mechanisms, by which we refer to such mechanisms that protect innovations and the related knowledge against imitation, and - building on this feature specifically - allow wider range of appropriation possibilities. Therefore, we do not consider complementary assets such as superior manufacturing, marketing, distribution, knowledge management systems, or creative processes, that may indeed increase appropriability in terms of

\footnotetext{
${ }^{1}$ In an effort to simplify, we differentiate between partners (that have complementary assets and operate in a different field for example being suppliers or other actors in the network of the focal company), and direct competitors (that have similar or almost similar capabilities and operate in the same field providing for the same clients) in this study. We thus in this study see the focal firm not collaborating with competitors but trying to prevent these independent competitors from imitating their innovations, and only collaborating with the partners, with whom they try to share knowledge responsibly and safely.

${ }^{2}$ Faems et al. (2003), for example note that using "inter-firm collaboration to support technological innovation can, on the other hand, also harm the innovation potential of organizations. Collaborations with competitors, for example, will bring along a risk of involuntary knowledge spillovers, especially when this knowledge has imperfect appropriability (Teece, 1986;Veugelers, 1998). This risk of opportunistic exploitation by partners can weaken the competitive position of the organization severely (Baum et al., 2000)." In line with this idea we think that companies may consider partners developing into future competitors already in the collaborative innovation phase, however, the focus of this paper is in the partners (and sharing intention) versus competitors (and imitation preventing) setting.
} 
profitability (Ahuja et al., 2013; James et al., 2013), but at the same time may actually reveal the essence of the innovation and thereby make it vulnerable to imitation.

Regarding those mechanisms that provide protection against imitative activities of competing organizations, earlier research has made certain categorizations: Gallié and Legros (2012) and Neuhäusler (2012), among others, make the distinction between formal and informal mechanisms. Legally granted and/or enforceable rights such as patents and other intellectual property rights (IPRs) and contracts are typically placed into the formal group, whereas (practical) secrecy (as opposed to legal trade secret that can be included into IPRs) (see Davis 2004 for practical protection of knowledge), human resource management (HRM) practices, and tacitness exhibit more firm-specific and therefore more informal nature. Formal and informal mechanisms can improve value capturing potential in the sense that they generate monopolistic arrangements (Teece, 1986), and can signal uniqueness and newness to stakeholder groups. Formal appropriability mechanisms help to legally appropriate value from the innovations created, whereas the informal mechanisms can support the formal ones in this process; they can keep the knowledge less observable ${ }^{3}$ until the value can be captured in the form of intellectual property rights, and before contracts have been signed related to value capturing. This is the basis for our first hypotheses, where we follow the earlier categorizations for simplicity:

Hypothesis 1a: IPRs and contracts as isolating appropriability mechanisms are positively related to value capture

Hypothesis $1 b$ : HRM, tacitness and secrecy as isolating appropriability mechanisms are positively related to value capture

Formal and informal mechanisms can also become relevant for value creation especially when it builds on prior innovation and knowledge and utilizing those, e.g., in collaboration and alliances with other actors (see Ahuja et al., 2013). In addition to functioning as a means to communicate about the resources and capabilities outside the firm boundaries so as to attract funding and partners for future innovation creation (see Mann and Sager, 2007; Pénin and Wack, 2008), the isolating appropriability mechanisms can serve to increase willingness of the firm to start new rounds of innovation: Prior experience of successful value creation and capture, financial resources generated from earlier innovation, and feeling of security with regard existing knowledge being protected when it is shared to others, can increase the tendency to engage in innovative activities (Ritala and Hurmelinna-Laukkanen, 2013). Although this description is somewhat biased, and sometimes exploration gets delayed due to current exploitation (and isolation perhaps intensifying it) (Hurmelinna-Laukkanen, 2012), we start our evaluation of the relationship between isolating appropriability mechanisms and value creation with the following hypotheses:

Hypothesis 2a: IPRs and contracts as isolating appropriability mechanisms are positively related to value creation

\footnotetext{
${ }^{3}$ Uniqueness can be preserved, for example, through the complexity created by tacitness of knowledge, using practical restrictions to such knowledge by passwords, or people knowledgeable of the innovation keeping it to themselves.
} 
Hypothesis 2b: HRM, tacitness and secrecy as isolating appropriability mechanisms are positively related to value creation

\subsection{Different strategic goals behind the use of formal and informal mechanisms - Different routes to value capturing and creation}

While we take the categorization of formal and informal mechanisms as the starting point for our examination for simplicity, we denote that these mechanisms differ clearly from each other also within the groups: For example, these mechanisms can be more or less visible to outsiders, or even within the firm, and they may differ in terms of the deliberateness in terms of use. What we mean by this is that, for example, it may be that an organization is simply incapable of transforming tacit knowledge into codified form, therefore unintentionally increasing the barriers to replication and imitation - and subsequently deterring building on the earlier findings. A collaboration partner, for example, might sense this, but hardly turns this against the focal firm and blames it for being reluctant to cooperate or behaving in opportunistic manner. On the other hand, over-protection built on IPRs, for example, may be both visible to outsiders and send a wrong signal: after all, it is expected that a firm can refrain from referring to its IPRs if it chooses to.

These specific features can well have an effect on value capturing and creation, and therefore, there is point in considering the different mechanisms also individually. Furthermore, in addition to these aspects, each isolating appropriability mechanism may connect to knowledge sharing and imitation with its own emphasis. For example, whereas IPRs are designed to provide protection against imitation (see e.g. Gilardoni, 2007, on defensive patenting as a weapon enabling companies to exclude competitors and secure large market share) their efficiency is sometimes questioned, and they are, in fact, acknowledged to be perhaps even more useful in securing controlled knowledge transfer (e.g., with regard licensing arrangements) (Cohen et al., 2000; Andries \& Faems, 2013). On the other hand, it is difficult to see how tacitness would, by nature, improve knowledge sharing efficiency, but it surely can provide an innovating organization with the needed protection against imitation (Szulanski, 2003; Zander \& Kogut, 1995). However, at the same time it needs to be remembered, that different mechanisms can be used simultaneously, and/or to cover different parts of an innovation and the related knowledge (Henkel et al., 2013; Hurmelinna-Laukkanen \& Puumalainen, 2007; James et al., 2013). Even the goals (imitation prevention, safe knowledge exchange, etc.) can vary for each mechanism. As little is still known on how different mechanisms relate to different strategic goals behind their use and how this, in the end, affects value capture and creation (Hall et al., 2012), we take an explorative stance to examine also interaction effects, and suggest the following:

Hypothesis 3a: Preventing imitation as a strategic goal for using IPRs and contracts, and HRM, tacitness and secrecy as isolating appropriability mechanisms moderates the relationship between those mechanisms and value capture

Hypothesis 3b: Enabling knowledge sharing as strategic goal for using IPRs and contracts, and HRM, tacitness and secrecy as isolating appropriability mechanisms moderates the relationship between those mechanisms and value capture 
Hypothesis 4a: Preventing imitation as strategic goal for using IPRs and contracts, and HRM, tacitness and secrecy as isolating appropriability mechanisms moderates the relationship between those mechanisms and value creation

Hypothesis 4b: Enabling knowledge sharing as strategic goal for using IPRs and contracts, and HRM, tacitness and secrecy as isolating appropriability mechanisms moderates the relationship between those mechanisms and value creation

While we search for simplicity with categorizations in our overall framework illustrated in Figure 1 below, in empirical examination, we will address the different mechanisms individually, yet taking them under scrutiny simultaneously.

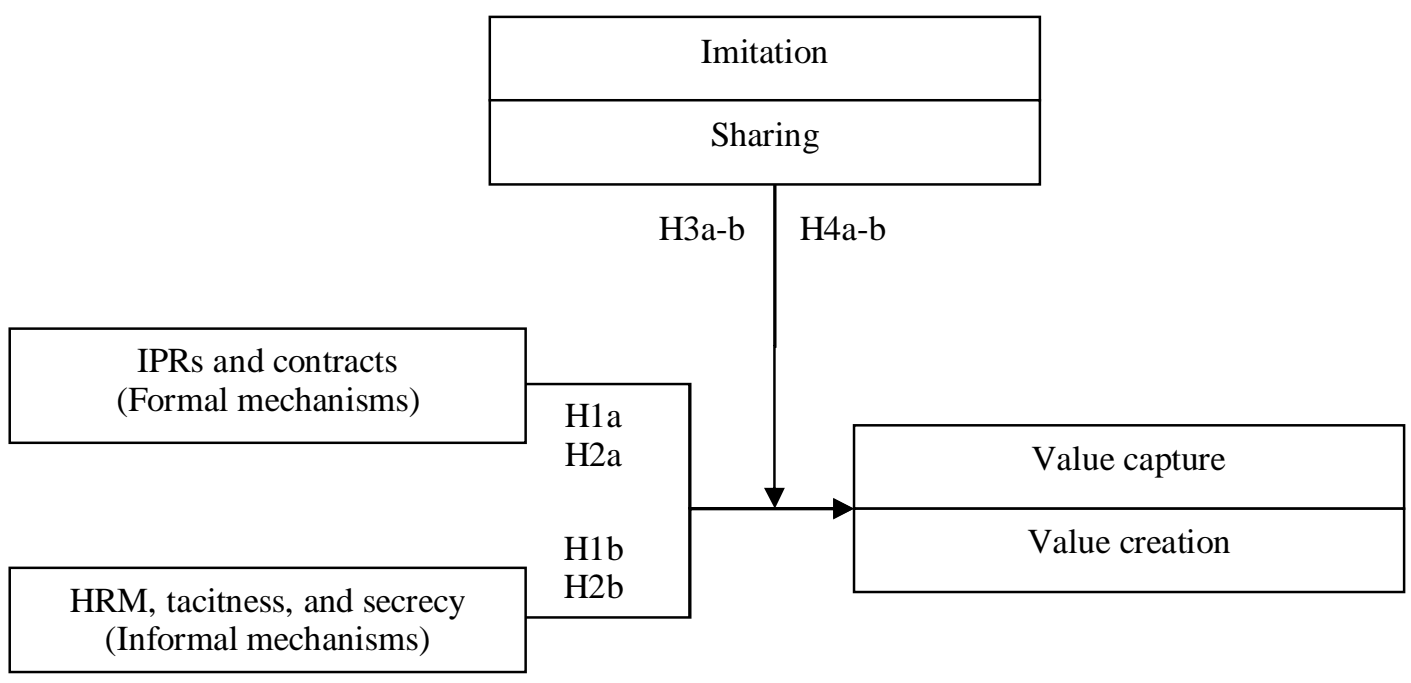

Figure 1 Research framework and hypotheses

\section{Methods}

\subsection{Sample and data collection}

We tested the hypotheses on survey data collected in Finland in 2008-2009. A structured web-based questionnaire was sent to key-informants in firms representing different industries. Amadeus database was used in identifying the companies for the initial population comprising a sample of Finnish companies engaged in R\&D (and with authority to affect those activities) and with at least 100 employees. 762 firms were considered suitable at that stage, and were subsequently contacted by telephone. Confidentiality was emphasised and a summary of the results was promised to the respondents that were found eligible during the call; 570 respondents were reached after several contact attempts. Of those contacted, 455 agreed to participate and 115 refused on the phone or when they received the questionnaire. Responses were received from 209 companies, representing a fairly satisfactory effective response rate of 36.7 per cent 
(209/570). Most respondents worked as chief executive officer, managing director, R\&D manager, or development officer, meaning that they should be knowledgeable with respect the issues under examination.

\subsection{Measures}

Dependent variables. We used value capture and value creation as our dependent variables. Value capture side, for us, is related to being successful in producing and using innovations commercially, keeping what has been created. Considering value creation side, we focus on the benefits retrieved from collaboration with other organizations. As we know that nowadays knowledge creation and utilisation leading to innovation does not happen in a vacuum (Luoma et al., 2010). According to Kettunen et al. (2007) effective networking is one of the most important factors contributing to innovation. Success in learning in network activities and building networks with other players with complementary capabilities contributes for successful value creation. The scale for the value capture measure was adapted from the work by Alegre et al. (2006) and Alegre \& Chiva (2008) and it contained seven items from responses to the question of "How would you compare your organization's performance over the last three years to that of other organizations operating in the same sector?" The respondents rated items on a sevenpoint Likert scale anchored with "performed very poorly" and "performed very well". The scale for value creation was adapted by Kale \& Singh (2007) and was measured by three items from responses to "How well do the following statements describe your alliances?" and items were rated on a seven-point Likert scale anchored with totally disagree and totally agree. Appendix 1 provides the wording of the items.

Independent variables. IPRs and contracts, and secrecy, HRM and tacitness as isolating appropriability mechanisms ${ }^{4}$ were covered by asking the respondents to assess the protective strength of the mechanisms they used in order to protect the firm's own innovations: "During the last three years, how well have the following mechanisms protected your innovations (products, services, processes) from imitation by competitors?" Respondents rated 18 items on a seven-point Likert scale (1=not applicable to our innovations, $2=$ poorly, $7=$ very well). The study conducted by HurmelinnaLaukkanen and Puumalainen (2007) and the Carnegie-Mellon Survey on industrial R\&D (see e.g., Cohen et al., 2000) were used in the item-development phase. The items for formal mechanisms covered IPRs ( 3 items) and contracts ( 2 items). The items for informal mechanisms concerned HRM (3 items), tacitness ( 7 items), and secrecy (3 items). (See Appendix 1 for the wording of the items.)

Moderating variables. We used preventing imitation as well as knowledge sharing as strategic goals and reasons to use of isolating appropriability mechanisms as moderator variables. Our moderating variables were adopted and modified from HurmelinnaLaukkanen and Puumalainen (2007). The measures for the strategic goals were constructed from responses to the question: "To what extent do the following statements

4 We acknowledge that appropriability is also, besides the managers' strategic choice (Pisano, 2006; Pisano \& Teece) also affected by industry architecture and environment (e.g. country/geographical scope). However, the single country setting of the research allows us to believe that the background of the companies in the sample is the same in terms of environment. As Finland is a small country with rather homogenous inhabitants and culture, we believe the way the managers see and understand appropriability issues is rather similar considering the Finnish legislation known to be relatively effective. 
characterise the protection of innovations in your company?" The respondents rated five items (two for preventing imitation and three for knowledge sharing) on a seven-point Likert-scale ( $1=$ totally disagree, $7=$ totally agree). Again, Appendix 1 shows the items.

\subsection{Assessment of bias}

The data relied on self-report measures, and therefore common method variance might have biased the findings. Common method bias is of particular concern when survey respondents are asked to fill out items covering both independent and dependent variables. We used Harman's one-factor test (Podsakoff et al., 2003) in order to assess the risk of such bias, and conducted a principal component analysis that incorporated all the items from all of the constructs. We investigated the solution in order to determine the number of factors required to account for the variance in all the items. We got a nine factor solution and the largest factor accounted for 23.8 per cent, which suggests that common method bias was not a concern.

\section{Results}

A model illustrating the hypothesized relationships was drafted, and the hypotheses were tested accordingly. We used Partial Least Squares (PLS) for the analyses, following the example of Chin et al. (2003). The first step was to assess the reliability and validity of the measurement models. We then used the structural model to test our hypotheses. In order to analyze the moderation effects, both the direct relations of the variables and the relation of the interaction term were examined (cf. Baron and Kenny, 1986).

\subsection{Correlation analysis}

Table 1 presents the correlation matrix, mean scores and standard deviations.

Table 1 Correlation matrix

\begin{tabular}{|c|c|c|c|c|c|c|c|c|c|c|}
\hline & Mean & $S D$ & 1 & 2 & 3 & 4 & 5 & 6 & 7 & 8 \\
\hline 1. HRM & 4.35 & 1.25 & & & & & & & & \\
\hline 2. Tacitness & 3.69 & 1.31 & $.429 * *$ & & & & & & & \\
\hline 3. Secrecy & 4.07 & 1.38 & $.371 * *$ & $.358 * *$ & & & & & & \\
\hline 4. IPRs & 3.01 & 1.51 & $.243 * *$ & $.168 *$ & $.277 * *$ & & & & & \\
\hline 5. Contracts & 4.70 & 1.44 & $.404 * *$ & $.368 * *$ & $.373 * *$ & $.376^{* * *}$ & & & & \\
\hline $\begin{array}{l}\text { 6. Value } \\
\text { creation }\end{array}$ & 4.87 & 1.12 & $.230 * *$ & .133 & -.101 & $-.06^{* * *}$ & .015 & & & \\
\hline $\begin{array}{l}\text { 7. Value } \\
\text { capture }\end{array}$ & 4.55 & 0.92 & $.412 * *$ & $.147^{*}$ & $.177 *$ & $.311 * *$ & $.285^{* *}$ & $.268 * *$ & & \\
\hline 8. Imitation & 4.13 & 1.57 & $.300 * *$ & $.250 * *$ & $.379 * *$ & $.548 * *$ & $.400 * *$ & .028 & $.285^{* * *}$ & \\
\hline 9. Sharing & 4.26 & 1.29 & $.345 * *$ & $.242 * *$ & $.363 * *$ & $.469 * *$ & $.323 * *$ & .041 & $.328 * *$ & $\begin{array}{r}.717 \\
* *\end{array}$ \\
\hline
\end{tabular}

Notes: $* *$ Correlation is significant at the 0.01 level; * Correlation is significant at the 0.05 level 


\subsection{Measurement models}

In order to test the measurement models, we assessed the internal consistency as well as the discriminant validity.

Internal consistency. Measures of construct reliability (CR) and convergent validity represent internal consistency. According to the $\mathrm{CR}$ test, all the constructs, with the exception of imitation, showed a value above the threshold of 0.7 as adopted by Bagozzi and Yi (1991) (see Appendix 1). Imitation just fell short of the threshold by the value of 0.67. In order to test for convergent validity we examined $\mathrm{CR}$, the factor loading and Average Variance Extracted (AVE). First, the loadings of all the items were high and statistically significant (see Appendix 1). This means that they were all related to their specific constructs, verifying the posited relationships among the indicators and constructs. Second, the AVE measure exceeded the cut-off point of 0.50 (see e.g., Fornell and Larcker, 1981) in most of our constructs. It fell short for value capture, but when all the criteria for convergent validity are taken into account, this measure is also applicable.

Discriminant validity indicates the extent to which any one construct differs from the others, and in assessing it the AVE should be greater than the variance shared between that construct and the other constructs in the model (i.e. the squared correlation between two constructs) (Fornell and Larcker, 1981). The constructs of our study fulfil this condition: when included all constructs used in our models (see Table 2) the diagonal elements (AVEs) are greater than the off-diagonal elements in the corresponding rows and columns.

Table 2 Discriminant validity

\begin{tabular}{lccrrrrrrr} 
& \multicolumn{1}{c}{1} & 2 & 3 & 4 & 5 & 6 & 7 & 8 & 9 \\
\hline 1. HRM & $\mathbf{. 6 0}$ & & & & & & & & \\
2. Tacitness & 0.18 & $\mathbf{. 5 9}$ & & & & & & & \\
3. Secrecy & 0.14 & 0.13 & $\mathbf{. 5 8}$ & & & & & & \\
4. IPRs & 0.06 & 0.03 & 0.08 & $\mathbf{. 5 7}$ & & & & & \\
5. Contracts & 0.16 & 0.14 & 0.14 & 0.14 & $\mathbf{. 5 7}$ & & & & \\
6. Value creation & 0.05 & 0.02 & 0.01 & 0.00 & 0.00 & $\mathbf{. 7 4}$ & & & \\
7. Value capture & 0.17 & 0.02 & 0.03 & 0.10 & 0.08 & 0.07 & $\mathbf{. 4 4}$ & & \\
8. Imitation & 0.09 & 0.06 & 0.14 & 0.30 & 0.16 & 0.00 & 0.08 & $\mathbf{. 5 3}$ & \\
9. Sharing & 0.12 & 0.06 & 0.13 & 0.22 & 0.10 & 0.00 & 0.11 & 0.51 & $\mathbf{. 7 4}$ \\
\hline
\end{tabular}

Notes: AVE associated with the construct is presented diagonally.

The squared correlations between the constructs are presented in the lower left triangle.

In sum, the model assessments gave good evidence of validity and reliability for the operationalization of the concepts.

\subsection{Testing the research models}

As Tables 3-6 show, our direct effect models for IPRs and contracts, and secrecy, HRM and tacitness as isolating appropriability mechanisms could explain 15 and 21 per cent and, respectively, 4 and 11 per cent of the variance in the value capture and value creation.

Empirical evidence indicates that both informal and formal mechanisms vary with respect to their effects on value creation and capture. The results were obtained by first estimating the direct effect path models reflecting the posited relationships between both two formal and three informal mechanisms and value capture in order to test Hypotheses 
1a and $1 \mathrm{~b}$. The path estimates from IPRs as well as from contracts to value capture were as hypothesized. The effects of IPRs $(B=0.259, \mathrm{p}<0.005)$ and contracts $(B=0.204, p<$ $0.01)$ had a positive impact $\left(\mathrm{R}^{2}=0.149\right)$ on value capture. Therefore, our Hypothesis $1 \mathrm{a}$ was supported. Out of informal mechanisms $\left(\mathrm{R}^{2}=0.211\right)$ only HRM $(B=0.468, p<0.005)$ plays a role (with positive effects), partially supporting our Hypothesis $1 \mathrm{~b}$ (see Tables 3 and 4).

Table 3 Testing the research models for formal protection mechanisms and value capture

\begin{tabular}{lcc} 
Path & Path coefficient & t-value \\
\hline Direct effect model & & \\
IPRs $\rightarrow$ Value capture & $.259^{* * *}$ & 3.450 \\
Contracts $\rightarrow$ Value capture & $.204^{* *}$ & 2.520 \\
$R^{2}$ & & .149 \\
Interaction model for Imitation & $.234^{* * *}$ & 2.895 \\
$\quad$ IPRs $\rightarrow$ Value capture & $.175^{*}$ & 2.166 \\
Contracts $\rightarrow$ Value capture & $.076 \mathrm{n} . \mathrm{s}$. & 1.215 \\
Imitation $\rightarrow$ Value capture & $-.142^{*}$ & 2.141 \\
IPRs X Imitation $\rightarrow$ Value capture & -.025 n.s. & 0.296 \\
Contracts X Imitation $\rightarrow$ Value capture & & .174 \\
$R^{2}$ & & \\
Interaction model for Sharing & $.178^{*}$ & 2.300 \\
IPRs $\rightarrow$ Value capture & $.158^{*}$ & 1.990 \\
Contracts $\rightarrow$ Value capture & $.204^{* *}$ & 2.555 \\
Sharing $\rightarrow$ Value capture & -.037 n.s. & 0.555 \\
IPRs X Sharing $\rightarrow$ Value capture & -.006 n.s. & 0.084 \\
Contracts X Sharing $\rightarrow$ Value capture & & .181 \\
$R^{2}$ & & \\
\hline
\end{tabular}

Notes: $* * *$ Significance $<0.005$; $* *$ Significance $<0.01$; $*$ Significance $<0.05$; a Significance $<$ 0.10

Table 4 Testing the research models for informal protection mechanisms and value capture

\begin{tabular}{lcc} 
Path & Path coefficient & t-value \\
\hline Direct effect model & & \\
HRM $\rightarrow$ Value capture & $.468^{* * *}$ & 7.213 \\
Tacitness $\rightarrow$ Value capture & $-.009 \mathrm{n} . \mathrm{s}$. & .147 \\
Secrecy $\rightarrow$ Value capture & $-.011 \mathrm{n} . \mathrm{s}$. & .236 \\
$R^{2}$ & & .211 \\
Interaction model for Imitation & $.425^{* * *}$ & \\
HRM $\rightarrow$ Value capture & $-.008 \mathrm{n} . \mathrm{s}$. & 6.562 \\
Tacitness $\rightarrow$ Value capture & $-.059 \mathrm{n} . \mathrm{s}$. & 0.141 \\
Secrecy $\rightarrow$ Value capture & $0.124^{*}$ & 1.208 \\
Imitation $\rightarrow$ Value capture & $-.023 \mathrm{n} . \mathrm{s}$. & 1.672 \\
HRM X Imitation $\rightarrow$ Value capture & $-.18^{*}$ & 0.397 \\
Tacitness X Imitation $\rightarrow$ Value capture & $-.069 \mathrm{n} . \mathrm{s}$. & 2.029 \\
Secrecy X Imitation $\rightarrow$ Value capture & & .974 \\
$R^{2}$ & .261 \\
Interaction model for Sharing & $.418^{* * *}$ & \\
HRM $\rightarrow$ Value capture & $-.041 \mathrm{n} . \mathrm{s}$. & 6.070 \\
Tacitness $\rightarrow$ Value capture & $-.066^{\mathrm{a}}$ & .687 \\
Secrecy $\rightarrow$ Value capture & $.151^{*}$ & 1.414 \\
Sharing $\rightarrow$ Value capture & $.084 \mathrm{n} . \mathrm{s}$. & 2.054 \\
HRM X Sharing $\rightarrow$ Value capture & $.22^{* * *}$ & .075 \\
Tacitness X Sharing $\rightarrow$ Value capture & & 2.662
\end{tabular}


Secondly, we estimated the direct effect path models reflecting the hypothesized relationships between formal and informal mechanisms and value creation for Hypotheses $2 \mathrm{a}$ and $2 \mathrm{~b}$ (see Tables 5 and 6). The results gave partial support to our Hypothesis $2 \mathrm{a}$ and to Hypothesis $2 \mathrm{~b}$. In the group of formal mechanisms, contracts $(\mathrm{B}=0.151, \mathrm{p}<0.05)(\mathrm{R} 2=0.035)$, and HRM $(\mathrm{B}=0.237, \mathrm{p}<0.005)$ and tacitness $(\mathrm{B}=0.157$, $\mathrm{p}<0.01)$ out of the informal mechanisms $(\mathrm{R} 2=0.113)$ have a positive effect on value creation, while secrecy $(B=-0.239, \mathrm{p}<0.005)$ and IPRs $(B=-0.177, \mathrm{p}<0.01)$ have, contrary to our hypotheses, an opposite effect.

Table 5 Testing the research models for formal protection mechanisms and value creation

\begin{tabular}{|c|c|c|}
\hline Path & Path coefficient & $\mathrm{t}$-value \\
\hline \multicolumn{3}{|l|}{ Direct effect model } \\
\hline IPRs $\rightarrow$ Value creation & $-.177 * *$ & 2.412 \\
\hline Contracts $\rightarrow$ Value creation & $.151 *$ & 1.910 \\
\hline$R^{2}$ & & .035 \\
\hline \multicolumn{3}{|l|}{ Interaction model for Imitation } \\
\hline IPRs $\rightarrow$ Value creation & $-.213 * *$ & 2.363 \\
\hline Contracts $\rightarrow$ Value creation & $.114^{\mathrm{a}}$ & 1.509 \\
\hline Imitation $\rightarrow$ Value creation & $.188 *$ & 2.257 \\
\hline IPRs X Imitation $\rightarrow$ Value creation & $-.105^{\mathrm{a}}$ & 1.523 \\
\hline Contracts X Imitation $\rightarrow$ Value creation & $.138 *$ & 1.873 \\
\hline$R^{2}$ & & .079 \\
\hline \multicolumn{3}{|l|}{ Interaction model for Sharing } \\
\hline IPRs $\rightarrow$ Value creation & $-.256 * * *$ & 2.683 \\
\hline Contracts $\rightarrow$ Value creation & $.134 *$ & 1.700 \\
\hline Sharing $\rightarrow$ Value creation & $.218 *$ & 2.275 \\
\hline IPRs X Sharing $\rightarrow$ Value creation & $.155^{*}$ & 2.081 \\
\hline Contracts X Sharing $\rightarrow$ Value creation & $.186 * *$ & 2.412 \\
\hline$R^{2}$ & & .105 \\
\hline
\end{tabular}

0.10

Table 6 Testing the research models for informal protection mechanisms and value creation

\begin{tabular}{lcc} 
Path & Path coefficient & t-value \\
\hline Direct effect model & $.237^{* * *}$ & 3.631 \\
HRM $\rightarrow$ Value creation & $.157^{* * *}$ & 2.309 \\
Tacitness $\rightarrow$ Value creation & $-.239^{* * *}$ & 2.585 \\
Secrecy $\rightarrow$ Value creation & & .113 \\
$R^{2}$ & & \\
Interaction model for Imitation & $.249^{* * *}$ & 3.685 \\
HRM $\rightarrow$ Value creation & $.135^{*}$ & 2.063 \\
Tacitness $\rightarrow$ Value creation & $-.237^{* * *}$ & 2.626 \\
Secrecy $\rightarrow$ Value creation & $.118^{*}$ & 1.792 \\
Imitation $\rightarrow$ Value creation & .019 n.s. & .338 \\
HRM X Imitation $\rightarrow$ Value creation & &
\end{tabular}




$\begin{array}{lcc}\text { Tacitness X Imitation } \rightarrow \text { Value creation } & .075 \mathrm{n} . \mathrm{s} . & 1.256 \\ \text { Secrecy X Imitation } \rightarrow \text { Value creation } & .162^{*} & 2.316 \\ R^{2} & & .162 \\ \text { Interaction model for Sharing } & .199^{* * *} & \\ \text { HRM } \rightarrow \text { Value creation } & .115^{*} & 2.796 \\ \text { Tacitness } \rightarrow \text { Value creation } & -.199^{* *} & 1.780 \\ \text { Secrecy } \rightarrow \text { Value creation } & .045 \mathrm{n} . \mathrm{s} . & 2.422 \\ \text { Sharing } \rightarrow \text { Value creation } & .092^{\mathrm{a}} & .775 \\ \text { HRM X Sharing } \rightarrow \text { Value creation } & .175^{* * *} & 1.297 \\ \text { Tacitness X Sharing } \rightarrow \text { Value creation } & -.165^{*} & 2.612 \\ \text { Secrecy X Sharing } \rightarrow \text { Value creation } & & 2.106 \\ R^{2} & & .173\end{array}$

Notes: $* * *$ Significance $<0.005 ; * *$ Significance $<0.01 ; *$ Significance $<0.05 ;{ }^{\text {a }}$ Significance $<$ 0.10

Next, we tested the possible moderation effects of two motives for using isolating appropriability mechanisms. More specifically, we tested whether preventing imitation and enabling knowledge sharing act as moderators between the different mechanisms and value capture/value creation. In our interaction models we tested two different models for each moderator-value capture and moderator-value creation combinations. First model included both IPRs and contracts (formal mechanisms) and the second one HRM, tacitness, secrecy (informal mechanisms). As Tables 3-6 show, our interaction models for imitation and sharing could explain around 20 per cent (formal mechanisms) and 30 per cent (informal mechanisms) of variance in value capture. Finally, interaction models for imitation and sharing could explain around 10 per cent (formal mechanisms) and 20 per cent (informal mechanisms) in value creation.

We got partial support for our Hypothesis 3a. Among formal mechanisms, imitation is a moderator $(\mathrm{B}=-0.142, \mathrm{p}<0.05)$ in the case of IPRs and value capture, with the size of the moderation effect 0.03, i.e., just above weak (Cohen and Cohen, 1983; Chin et al., 2003). Among informal mechanisms there were no moderation effects. In addition, based on our analysis our Hypothesis $3 \mathrm{~b}$ was rejected as there was no moderation effect of enabling knowledge sharing as strategic goal on value capture with the use of formal or informal mechanisms. See Tables 3 and 4 for the results.

As hypothesized, in the relationship between formal and informal mechanisms and value creation, preventing imitation as strategic goal is a moderator (see Tables 5 and 6 above). Based on our analysis, preventing imitation moderated some of the relationships between formal and informal mechanisms and value creation. Therefore, we got partial support for our Hypothesis 4a: Among formal mechanisms, the results give a path coefficient of $-0.105(\mathrm{p}<0.10)$ for interaction effect for IPRs and $0.138(\mathrm{p}<0.05)$ for contracts. The size of the moderation effect for the model including formal mechanisms was 0.05. Among informal mechanisms preventing imitation by competitors only moderates the relationship between secrecy and value creation $(B=0.162, p<0.05)$ with the moderation effect between weak and moderate size (0.06). Finally, we got full support for our Hypothesis $4 \mathrm{~b}$. As assumed, knowledge sharing is a moderator between both formal and informal mechanisms and value creation. Knowledge sharing moderated relationship between both formal mechanisms: IPRs $(B=0.155, \mathrm{p}<0.05)$ and contracts $(B=0.186, p<0.01)$. Among the informal mechanisms the results give a path coefficient of $0.092(p<0.1)$ in HRM, $0.175(p<0.005)$ in tacitness, and $-0.165(p<0.05)$ in secrecy. For formal mechanisms the size of the moderation effect $(0.03)$ was weak and in informal mechanisms (0.07) between weak and moderate. 


\subsection{Summary on findings related to the moderation effects}

The strategic goals (reducing imitation by competitors or securing knowledge sharing to partners) of the firms in using appropriability mechanisms seem to have some effects, as the interaction terms suggest that the forms of the relationships (see Prescott, 1986) are slightly different when reducing imitation and knowledge sharing as strategic goals are taken under consideration.

In terms of value capture, the interaction effects are less important at least in terms of the secrecy, HRM and tacitness as isolating appropriability mechanisms. For these mechanisms there are no statistically significant interaction effects for either reducing imitation by competitors or improving safety of knowledge sharing. For formal mechanisms there was only one statistically significant interaction effect: the effect of IPRs on value capture turns out negative and in the case of high IPR usage the slope becomes considerably steeper (compared to the low IPR usage) when the strategic goal related to using appropriability mechanisms is to reduce imitation by competitors. See a graphical interpretation of this in Figure 2. This could indicate, in line with a range of recent research, that the value of IPRs in preventing imitation is somewhat questionable (e.g. Sattler, 2003).

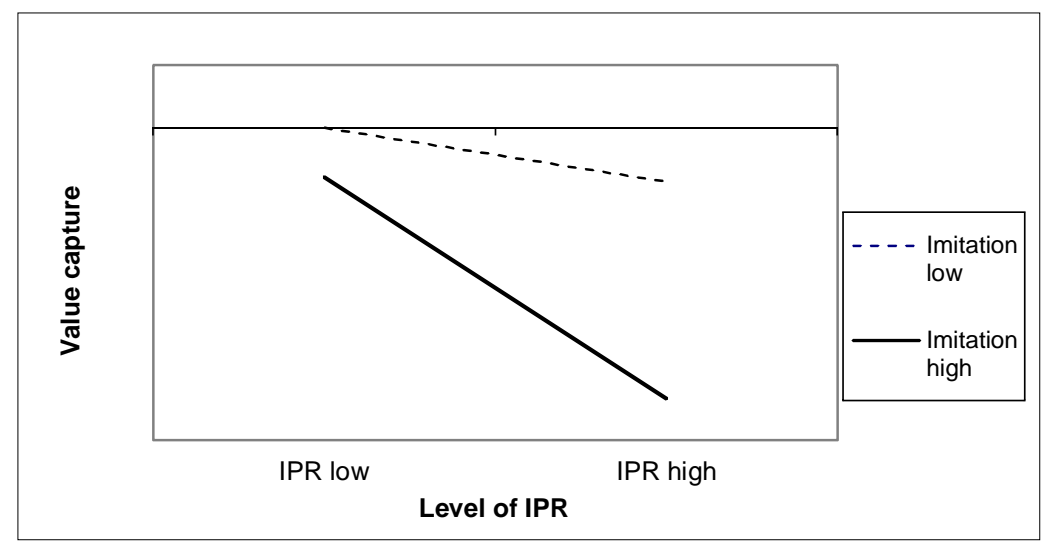

Figure 2 A graphical interpretation of interaction effect of imitation in the IPR-value capture relationship (the horizontal line indicates that some of the values for IPR low were above zero).

Considering value creation, it seems that if the goal is reducing imitation by competitors, then the relationships between informal secrecy, and formal IPRs and contracts and value creation are affected by the strategic goal of use (in the case of secrecy and contracts the effect is positive, and with IPRs it is negative). In fact, in the case of secrecy the direct negative effect turns into positive one when the aim actually is to reduce imitation. Figure 3 shows the graphical interpretation of this. Paying attention to the strategic goals behind use of secrecy, companies may recognize who they actually want to protect the knowledge from, i.e., competitors, not alliance partners. That then leads to more positive results in value creation with alliance partners. 


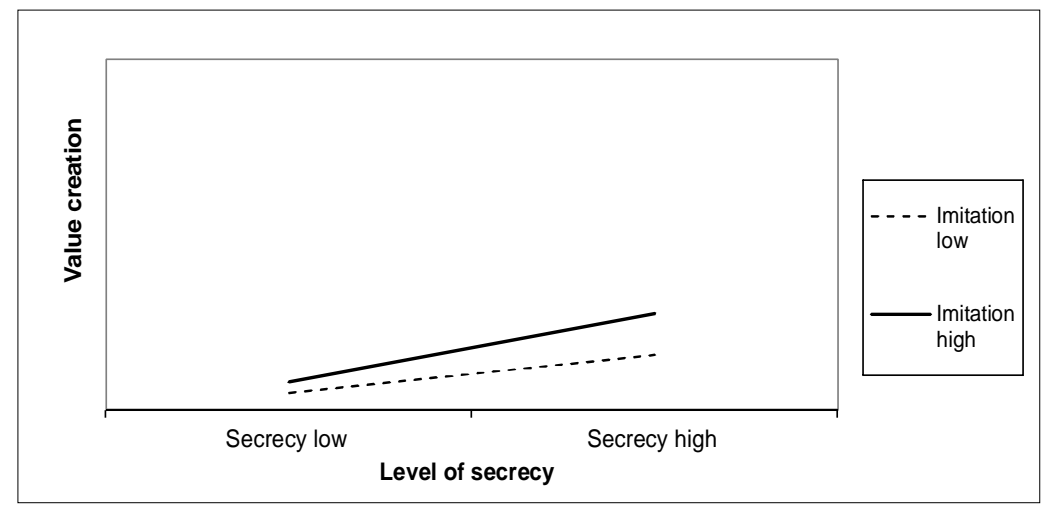

Figure 3 A graphical interpretation of interaction effect of imitation in the Secrecy-value creation relationship

On the other hand, if the purpose is to enable safe knowledge sharing with one's partners, the effects of HRM, tacitness, and secrecy on value creation are affected by this strategic goal behind their use. However, whereas the other informal mechanisms have a positive sign, the secrecy variable becomes negative (see Figure 4 for a graphical interpretation). We think that this could be because secrecy involves the use of practices that limit the knowledge sharing de facto, whereas the company's motivation related to using protection mechanisms is here to enable and help the secure knowledge sharing to partners. Reliance on secrecy could harm this endeavor. In particular, problems likely emerge when partners become aware of the knowledge concealment practices of the firm. This means that the more important the firm considers the knowledge sharing motivation in using protection mechanisms to be, the more harmful the effect of secrecy on value creation is.

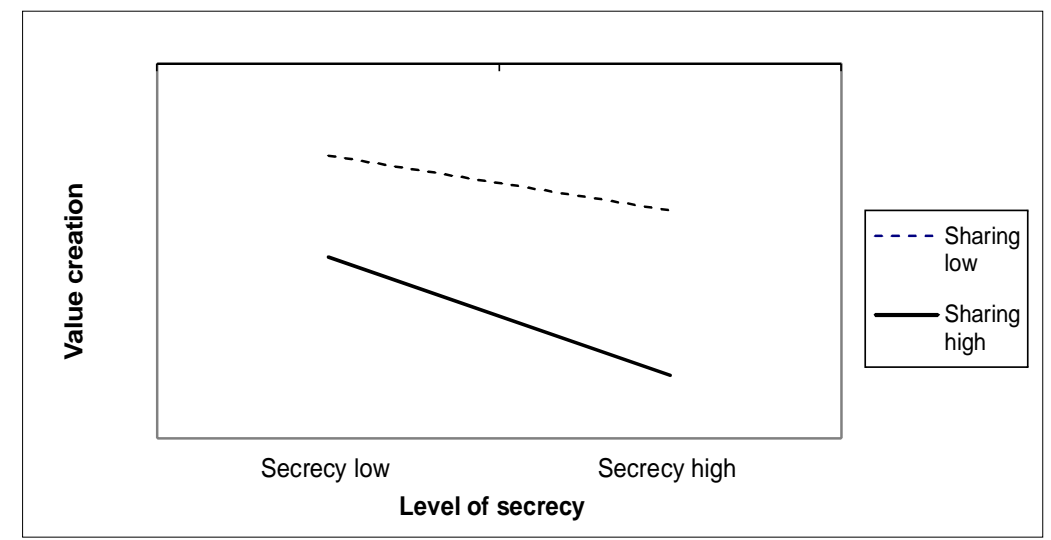

Figure 4 A graphical interpretation of interaction effect of sharing in the Secrecy-Value creation relationship.

Also in the case of both IPRs and contracts, and value creation, the relationships are affected by the strategic goal. For contracts, the sharing intention can be communicated with contracts, which then improves the value creation potential. The interaction effect for IPRs is also positive (see Figure 5). While it could seem paradoxical that the firm uses 
more IPRs when it wants to share with its partners, the logic behind this is that the IPRs enable the safe transfer of knowledge to partners. When used for this particular purpose, the outcomes can be notably better compared to a situation where preventing imitation is the goal.

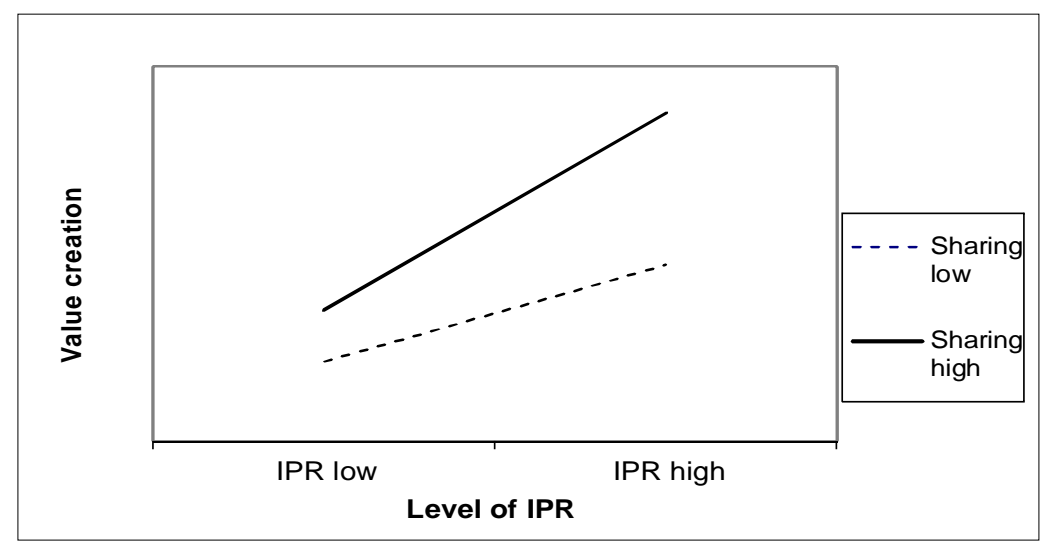

Figure 5 A graphical interpretation of interaction effect of sharing in the IPR-Value creation relationship.

In sum, the interplay with isolating appropriability mechanisms and strategic goals of companies related to their use for either reducing imitation by competitors or for enabling safe knowledge sharing to collaboration partners seems more relevant for the process of value creation than for value capture considering both types of appropriability mechanisms.

\section{Discussion and implications}

In this study, we address the call for further research by Ahuja et al. (2013) and other authors, who leave it to further research to discuss mechanisms other than organization structures, knowledge management systems, creative processes, resources, division of inventive labor, retention-oriented HR practices, invention domain, supporting assets, or R\&D alliances as determinants of overall innovation appropriability. Our study contributes to existing knowledge by concentrating on isolating appropriability mechanisms that build on protective power and focus on the innovation and the related knowledge, and by showing not only that a range of mechanisms can actually be utilized (cf., e.g, Teece 1986), but that formal and informal mechanisms may have different kinds of effects on value creation and value capture, especially depending on their strategic uses (see Hall et al., 2012).

For example, we found secrecy to exhibit a direct negative effect on value creation, and but no effect on value capture. Another example is the case of IPRs having a negative direct connection with value creation, and a positive connection with value capture, where as contracts positively affect both value creation and capture. IPRs and secrecy may, in fact, make value creation harder, especially if the protective side and firmspecific utilization of the protected innovation get highlighted. At the same time they may allow efficient value capturing if the IPRs signal quality and uniqueness to customers and 
enable the innovating firm to become the sole beneficiary. On the other hand, contracts can be used to determine the rights and obligations of the contracting parties, thereby not only allowing value capturing based on controllability of the innovation to be profited from, but also enhancing collaboration with partners that potentially offer valuable assets for future innovation creation.

Surely, the purpose for which the isolating appropriability mechanisms are used is of relevance. One finding is that deliberate and consistent use of formal mechanisms for knowledge sharing can actually enhance collaboration with alliance partners and therefore positively affect value creation (cf. Belderbos et al., 2013). Also not finding statistically significant relationships reveals interesting aspects: For example, tacitness in principle yields quite similar results as secrecy in terms of making knowledge transfer harder, but as it may not be deemed as intentional (as it can be seen as the inherent quality of the knowledge and not so much a mechanism to be actively used), it might not have such a negative effect on collaborative endeavours and subsequent value creation (cf. Hannah, 2005). Value capture side can be supported with IPRs, contracts, and human resource management practices, but again, care has to be taken not to overemphasize preemptive activities (cf. Ceccagnoli, 2008) which might easily turn positive effects into negative ones.

This study, as any other, has its limitations. Firstly, our data was gathered in Finland representing a single western country. The results might be different in countries with different cultural backgrounds and legal systems. This could be an interesting avenue for further studies. Secondly, in our research setting both independent and dependent variables were retrieved from the same respondent. This is also a concern in terms of possible common method bias. Although based on the tests we have conducted it is not a major problem in this study, we suggest that to improve methodological rigor, in future studies independent and dependent variables should be collected from different respondents. Further studies could also identify and utilize more objective measures of both value capture and value creation. Finally, it might be worthwhile to study this phenomenon also with different units of analysis. For example, the unit of analysis could be a single project where the different mechanisms have been used. This would widen the understanding on the relationship between different mechanisms and value capture/creation and the moderating role of the motives in that relationship. Moreover, also qualitative methods on few selected cases could offer deeper insight on the dynamics of these mechanisms and how the use of different mechanisms, for example, are interpreted by partners and through which kinds of processes the different mechanisms affect the value capture and creation. The research conducted in this study, and its limitations, provide grounds for such further research.

\section{References}

Alegre, J. Lapiedra, R. \& Chiva, R. (2006). A measurement scale for product innovation performance. European Journal of Innovation Management, 9, 333-346.

Alegre, J. \& Chiva, R. (2008). Assessing the impact of organizational learning capability on product innovation performance: An empirical test. Technovation, 28. 315326.

Andries, P., \& Faems, D. (2013). Patenting activities and firm performance: Does firm size matter?. Journal of Product Innovation Management, 30, 6, 1089-1098. 
Ahuja, G., Lampert, C.M. \& Novelli, E. (2013). The second face of appropriability: generative appropriability and its determinants, Academy of Management Review, 38, 2, 248-269.

Bagozzi, R. P. \& Yi, Y. (1991). Multitrait-Multimethod Matrices in Consumer Research, Journal of Consumer Research, 17, 4, 426-39.

Baron, R.M \& Kenny, D.A (1986). The moderator-mediator variable distinction in social psychological research: conceptual, strategic, and statistical considerations, Journal of Personality and Social Psychology, 51, 6, 1173-1182.

Baum, J.A.C., Calabrese, T. \& Silverman, B.S. (2000). Don't go it alone: alliance network composition and startups' performance in Canadian biotechnology. Strategic Management Journal, 21, 3, 267-294.

Belderbos, R., Cassiman, B., Faems, D., Leten, B., \& Van Looy, B. (2013). Coownership of intellectual property: Exploring the value-appropriation and value-creation implications of co-patenting with different partners. Research Policy.

Bessen, J. \& Maskin, E. (2009). Sequential innovation, patents, and imitation. The RAND Journal of Economics, 40, 611-635.

Bhatt, G. D. (2000). A resource-based perspective of developing organizational capabilities for business transformation, Knowledge and Process Management, 7, 2, 119129.

Ceccagnoli, M. (2008). Appropriability, preemption, and firm performance, Strategic Management Journal, 30, 81-98.

Chin, W. W., Marcolin, B. L. \& Newsted, P. N. (2003). A partial least squares latent variable modelling approach for measuring interaction effects: results from a monte carlo simulation study and an electronic-mail emotion/adoption study. Information System Research, 14, 2, 180-217.

Cohen, W.M., Nelson, R.R. \& Walsh, J.P. (2000). Protecting their intellectual assets: appropriability conditions and why U.S. manufacturing firms patent (or not). Working Paper 7552, National Bureau of Economic Research, Inc.

Cohen, J. and Cohen, P. (1983). Applied Multiple Regression/Correlation Analysis for the Beahvioral Sciences, Second Edition. Hillsdale, New Jersey: Lawrence Erlbaum Associates.

Davis, L. (2004) Intellectual Property Rights, Strategy and Policy, Economics of Innovation and New Technology, 13, 5, 399-415.

Dhanaraj, C \& Parkhe, A (2006). Orchestrating innovation networks. Academy of Management Review, 31, 659-669.

Faems, D., Janssens, M., \& Van Looy, B. (2003). Linking technological innovation and inter-organizational collaboration: an overview of major findings. Working Paper Steunpunt OOI (March).

Faems, D., Janssens, M., \& Van Looy, B. (2007). The initiation and evolution of interfirm knowledge transfer in R\&D relationships. Organization Studies, 28, 11, 16991728.

Fleming, L. (2001). Recombinant uncertainty in technological search. Management Science, 47: 117-132.

Fornell, C. \& Larcker, D. F. (1981), Evaluating Structural Equation Models with Unobservable Variables and Measurement Error, Journal of Marketing Research, 18(1): 39-50.

Gallié, E-P. \& Legros, D. (2012). French firms' strategies for protecting their intellectual property, Research Policy, 41, 780-794. 
Gilardoni, E. (2007). Basic approaches to patent strategy, International Journal of Innovation Management, 11(3): 417-440.

Hall, B.H., Helmers, C., Rogers, M. \& Sena, V. (2012). The choice between formal and informal intellectual property: A literature review. NBER Working Paper Series, WP 17983.

Hannah, D.R. (2005). Should I keep a secret? The effects of trade secret protection procedures on employees' obligations to protect trade secrets, Organization Science, 16, $1,71-84$.

Henkel, J., Baldwin, C.Y. \& Shih, W. (2013). IP Modularity: Profiting from innovation by aligning product architecture with intellectual property. California Management Review, 55, 4, 65-82.

Hurmelinna-Laukkanen, P. (2012). Constituents and outcomes of absorptive capacity - Appropriability regime changing the game, Management Decision, 50, 7, 1178 - 1199.

Hurmelinna-Laukkanen, P. \& Puumalainen K. (2007). The nature and dynamics of appropriability - Strategies for appropriating returns on innovation. R\&D Management, 37(2): 95-112.

James, S. D., Leiblein, M. J., \& Lu, S. (2013). How firms capture value from their innovations. Journal of management, 39, 5, 1123-1155.

Kale, P. \& Singh, H. (2007). Building firm capabilities through learning: The role of the alliance learning process in alliance capability and firm-level alliance success. Strategic Management Journal, 28, 981-1000.

Kettunen, J., Ilomäki, SK \& Kalliokoski, P. (2007). Making Sense of Innovation Management. Publication, Helsinki, Teknologiainfo Teknova.

Luoma, T., Paasi, J. \& Valkokari, K. (2010). Intellectual property in interorganisational relationships - Finding from an international study, International Journal of Innovation Management, 14(3): 399-414.

Mann, R. J. \& Sager, T. W. (2007). Patents, venture capital, and software start-ups. Research Policy, 36, 2, 193-208.

McEvily, S.K., Eisenhardt, K.M. \& Prescott, J.E. (2004). The global acquisition, leverage, and protection of technological competencies. Strategic Management Journal, 25, 713-722.

Neuhäusler, P. (2012). The use of patents and informal appropriation mechanisms differences between sectors and among companies. Technovation, 32, 681-693.

Pénin J. \& Wack JP. (2008). Research tool patents and free-libre biotechnology: A suggested unified framework. Research Policy, 37, 1909-1921.

Perkmann, M. (2009). Trading off revealing and appropriating in drug discovery: The role of trusted intermediaries. In Academy of Management Best Paper Proceedings, 1-6.

Pisano, G.P., (2006). Profiting from innovation and the intellectual property revolution. Research Policy, 35, 1122-1130.

Pisano, G.P. \& Teece, D.J. (2007). How to capture value from innovation: Shaping intellectual property and industry architecture, California Management Review, 50(1): 278-296.

Podsakoff, P.M., MacKenzie, S.B., Lee, J.-Y. \& Podsakoff, N.P. (2003). Common Method Biases in Behavioral Research: A Critical Review of the Literature and Recommended Remedies. Journal of Applied Psychology, 88, 879-903.

Ritala, P. \& Hurmelinna-Laukkanen, P. (2013). Incremental and Radical Innovation in Coopetition - The Role of Absorptive Capacity and Appropriability. Journal of Product Innovation Management, 30,1,154-169. 
Sattler, H. (2003). Appropriability of product innovations: An empirical analysis for Germany. International Journal of Technology Management, 26, 5, 502-516.

Szulanski, G. (2003). Sticky Knowledge: Barriers to Knowing in the Firm. Sage Publications Ltd. London, UK.

Teece, D.J. (1986). Profiting from technological innovation: Implications for integration, collaboration, licensing and public policy. Research Policy, 15, 285-305.

Thomä, J. \& Bizer, K. (2013). To protect of not to protect? Modes of appropriability in the small enterprise sector. Research Policy, 42, 35-49.

Veugelers R. (1998) Collaboration in R\&D: an assessment of theoretical and empirical findings. The Economist, 149, 419-443.

Zander, U. \& Kogut, B. (1995). Knowledge and the speed of the transfer and imitation of organizational capabilities: An empirical test, Organization Science, 6, 1, 7692. 
Appendix 1. Measurement items

\begin{tabular}{|c|c|c|c|c|}
\hline Concept & Item & $\begin{array}{l}\text { Factor } \\
\text { loading }\end{array}$ & $A V E$ & $C R$ \\
\hline \multirow{3}{*}{ HRM } & Educating personnel on IPR and secrecy issues & $.804 * * *$ & \multirow{3}{*}{60} & \multirow{3}{*}{.82} \\
\hline & $\begin{array}{l}\text { Making personnel committed to the firm (e.g. by offering } \\
\text { perks) }\end{array}$ & $.819 * * *$ & & \\
\hline & Small personnel turnover/minimizing it & $.689 * * *$ & & \\
\hline \multirow{6}{*}{ Tacitness } & The fact that it is difficult for customers to switch providers & $.563 * * *$ & \multirow{6}{*}{.59} & \multirow{6}{*}{.91} \\
\hline & Complexity of the product/service/process & $.871 * * *$ & & \\
\hline & $\begin{array}{l}\text { The fact that it is very hard to teach knowledge related to the } \\
\text { product/service/process }\end{array}$ & $.920 * * *$ & & \\
\hline & $\begin{array}{l}\text { The fact that it is very hard to understand the features of the } \\
\text { product/service/process by } \\
\text { observing/examining it } \\
\text { The fact that knowledge related to the } \\
\text { product/service/process may not be usable in } \\
\text { other environments }\end{array}$ & $.884 * * *$ & & \\
\hline & $\begin{array}{l}\text { The fact that it is not possible to document knowledge } \\
\text { related to the product/service/process. }\end{array}$ & $.677 * * *$ & & \\
\hline & $\begin{array}{l}\text { The fact that core knowledge related to the } \\
\text { product/service/process is embedded in routines }\end{array}$ & $.518 * * *$ & & \\
\hline \multirow{3}{*}{ Secrecy } & Sharing information with just a few & $.430 * * *$ & \multirow{3}{*}{.58} & \multirow{3}{*}{.80} \\
\hline & Using passwords & $.891 * * *$ & & \\
\hline & Restricting access to meetings and the firm's premises & $.881 * * *$ & & \\
\hline \multirow{3}{*}{ IPRs } & Patents & $.610^{* * *}$ & \multirow{3}{*}{.57} & \multirow{3}{*}{.79} \\
\hline & Copyright & $.977 * * *$ & & \\
\hline & Trademark & $.626 * * *$ & & \\
\hline \multirow{2}{*}{ Contracts } & Long-term collaboration contracts & $.978 * * *$ & \multirow{2}{*}{.57} & \multirow{2}{*}{.70} \\
\hline & Non-disclosure/confidentiality agreements & $.426 * * *$ & & \\
\hline \multirow[t]{2}{*}{$\begin{array}{l}\text { Value } \\
\text { creation }\end{array}$} & $\begin{array}{l}\text { Our company has achieved its primary objectives in forming } \\
\text { alliances } \\
\text { The company's competitive position has been greatly } \\
\text { enhanced due to alliances }\end{array}$ & $.830 * * *$ & \multirow[t]{2}{*}{.74} & \multirow[t]{2}{*}{.89} \\
\hline & $\begin{array}{l}\text { The company has been successful in learning some critical } \\
\text { skills and capabilities from its alliance partners }\end{array}$ & $.815^{* * *}$ & & \\
\hline \multirow{7}{*}{$\begin{array}{l}\text { Value } \\
\text { capture }\end{array}$} & Replacement of products being phased out & $.666 * * *$ & \multirow{7}{*}{.44} & \multirow{7}{*}{.85} \\
\hline & Replacement of services being phased out & $.738 * * *$ & & \\
\hline & Extension of product/service range within main market & $.708 * * *$ & & \\
\hline & Extension of product/services range outside main market & $.660 * * *$ & & \\
\hline & Development of environment-friendly products/services & $.626 * * *$ & & \\
\hline & Opening of new markets abroad & $.516^{* * * *}$ & & \\
\hline & Opening of new domestic target groups & $.723 * * *$ & & \\
\hline Imitation & $\begin{array}{l}\text { Protecting innovative products/services/processes helps } \\
\text { prevent their copying and imitation } \\
\text { With protection we get better results, when competitors do } \\
\text { not introduce comparable products/services }\end{array}$ & $.422 * * *$ & .53 & .67 \\
\hline \multirow{3}{*}{ Sharing } & $\begin{array}{l}\text { Protecting innovative products/services/processes helps } \\
\text { improve the company's reputation with stakeholder groups }\end{array}$ & $.847 * * *$ & \multirow{3}{*}{.74} & \multirow{3}{*}{.90} \\
\hline & $\begin{array}{l}\text { Protecting knowledge and innovations makes collaboration } \\
\text { with different organizations more manageable }\end{array}$ & $.892 * * *$ & & \\
\hline & $\begin{array}{l}\text { Protecting knowledge and innovations makes collaboration } \\
\text { safer. }\end{array}$ & $.844 * * *$ & & \\
\hline
\end{tabular}

**** Statistically significant at a 0.005 significance level. 